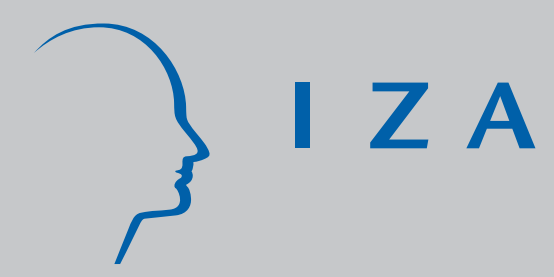

IZA DP No. 1000

Experiments on Unemployment Benefit

Sanctions and J ob Search Behavior

\author{
J an Boone \\ Abdolkarim Sadrieh \\ J an C. van Ours \\ J anuary 2004
}




\title{
Experiments on Unemployment Benefit Sanctions and Job Search Behavior
}

\author{
Jan Boone \\ CentER, Tilburg University, TILEC, \\ ENCORE, CEPR and IZA Bonn \\ Abdolkarim Sadrieh \\ CentER, Tilburg University \\ Jan C. van Ours \\ CentER, Tilburg University, OSA, \\ CEPR and IZA Bonn
}

\section{Discussion Paper No. 1000 \\ January 2004}

IZA

P.O. Box 7240

53072 Bonn

Germany

Phone: +49-228-3894-0

Fax: +49-228-3894-180

Email: iza@iza.org

Any opinions expressed here are those of the author(s) and not those of the institute. Research disseminated by IZA may include views on policy, but the institute itself takes no institutional policy positions.

The Institute for the Study of Labor (IZA) in Bonn is a local and virtual international research center and a place of communication between science, politics and business. IZA is an independent nonprofit company supported by Deutsche Post World Net. The center is associated with the University of Bonn and offers a stimulating research environment through its research networks, research support, and visitors and doctoral programs. IZA engages in (i) original and internationally competitive research in all fields of labor economics, (ii) development of policy concepts, and (iii) dissemination of research results and concepts to the interested public.

IZA Discussion Papers often represent preliminary work and are circulated to encourage discussion. Citation of such a paper should account for its provisional character. A revised version may be available on the IZA website (www.iza.org) or directly from the author. 
IZA Discussion Paper No. 1000

January 2004

\section{ABSTRACT \\ Experiments on Unemployment Benefit Sanctions and Job Search Behavior*}

This paper presents the results of an experimental study on unemployment benefit sanctions. The experimental set-up allows us to distinguish between the effect of benefit sanctions once they are imposed (the ex post effect) and the effect that unemployed want to avoid getting a benefit sanction imposed (the ex ante effect). We find that both effects matter. Moreover, the ex ante effect turns out to be substantial and bigger than the ex post effect. Benefit sanctions stimulate the outflow from unemployment.

JEL Classification: $\quad$ C91, J64, J65

Keywords: experiments, unemployment benefits, sanctions, job search

Corresponding author:

Jan C. van Ours

Department of Economics

Tilburg University

P.O. Box 90153

5000 LE Tilburg

The Netherlands

Email: vanours@uvt.nl

* Jan Boone would like to thank NWO, KNAW and VSNU for financial support through a Vernieuwingsimpuls grant. 


\section{Introduction}

Despite the fact that over the past decades unemployment went down in many OECD countries it is still high in most of these countries. Governments face the problem of how to design policies that bring unemployed back to work more quickly. It turns out that many of the active labor market policies that are used (training, subsidized jobs et cetera) have insufficient effects on overall unemployment (Martin and Grub, 2001). One of the problems is that in many countries there are substantial unemployment benefits for those who loose their jobs. Furthermore, in some countries these unemployment benefits are provided for a long period.

One of the policies that does seem to bring unemployed back to work more quickly is a system of monitoring and benefit sanctions. ${ }^{1}$ The evidence on the effectiveness of benefit sanctions is partly based on empirical research in which micro data about unemployment durations and benefit sanctions are used. Abbring et al. (1997) and Van den Berg et al. (1998) provide empirical evidence for the Netherlands. Jensen et al. (1999) does the same for Denmark and Lalive et al. (2002) presents an analysis for Switzerland. These micro econometric studies typically compare unemployed with and unemployed without benefit sanctions, taking into account that the process by which sanctions are imposed may have been selective. Therefore these studies provide estimates of the so called ex post effect, that is the effect of benefit sanctions once they are imposed.

These studies, however, do not provide information about the so called ex ante effect, that the mere existence of a system of monitoring and benefit sanctions may affect the outflow from unemployment even before a benefit sanction is imposed because the unemployed want to avoid being confronted with a benefit sanction. ${ }^{2}$ This ex ante effect can be formalized in a number of different ways. In papers like Boone and Van Ours (1999) and Boone et al. (2001) the ex ante effect appears because by searching harder the unemployed can reduce the probability of being sanction. The idea is that government officials monitor search effort. When the effort is (perceived to be) high, they conclude that

\footnotetext{
${ }^{1}$ See Fredriksson and Holmlund (2003) for an overview of research on unemployment benefits including benefit sanctions and Grubb (1999) for an overview of the situation on monitoring and benefit sanctions across the OECD.

${ }^{2}$ Lalive et al. (2002) present an attempt to estimate the ex ante effect using cross sectional variation in the sanction rate. Black et al. (2003) show that an ex ante effect may also occur when unemployed workers are assigned to training programs. To avoid entering such programs they leave unemployment more quickly than without the assignment.
} 
someone did not get a job, because none were available, not because he did not try to find a job. Using this set up Boone et al. (2001) shows that it is optimal from a welfare point of view to introduce a system of benefit sanctions. Boone and Van Ours (1999) shows that the strength of the ex ante effect and the ex post effect depends on the monitoring intensity. If this intensity is low, the ex post effect is more important, but if the monitoring intensity is high, the ex ante effect is more important. In the model presented in this paper, the unemployed cannot affect the probability of being sanctioned, except by accepting the current wage offer. This leads to slightly different results as explained below.

This paper reports a laboratory experiment to analyze the effects of unemployment benefit sanctions. We investigate the effect of benefit sanctions using a search-theoretic framework. Previous experimental investigations of search models are reported in Braunstein and Schotter (1981, 1982), Hey (1982, 1987), Cox and Oaxaca $(1989,1992)$, and Sonnemans (1998). In general, all authors conclude that observed behavior is close to, but not fully consistent with optimal search behavior. Braunstein and Schotter $(1981,1982)$ test the theoretical implications of numerous variants of an infinite horizon sequential job search model. They observe that individuals react to variations of the environment as predicted by theory, even though the duration of search often falls short of the theoretically predicted duration. Additionally, they find reservation wages to drop over time, even though theory predicts constant reservation wages in the infinite horizon models that they use as benchmarks.

Cox and Oaxaca $(1989,1992)$ report job search experiments in a finite horizon model. They argue that the individuals in Braunstein and Schotter's (1981, 1982) experiments had not actually believed in the infinite horizon and had rather played a finite horizon game, in which optimal reservation wages fall over time. While they find search duration and income to be very close to the theoretical predictions with risk-neutral individuals (Cox and Oaxaca 1989), they also find the directly elicited reservation wages to be lower than predicted (Cox and Oaxaca 1992). They conclude that a model with risk aversion explains their observations best.

Sonnemans (1998), however, shows that a fully rational model of risk averse search is not consistent with the search strategies that participants choose in a finite search model experiment. Most individuals in his experiment use search heuristics that combine the rational marginal net benefit aspect with some satisficing rule that is applied to total income (i.e. they do not ignore the sunk 
cost of search). This observation is well in line with the results of Hey's (1982, 1987) research on consumer search heuristics.

Our paper contributes to the experimental literature on job search in three important ways. First, the model we use seems especially suited for an experimental implementation, because it provides a constant reservation wage benchmark in a finite horizon setting. ${ }^{3}$ The models implemented so far had either the one or the other advantage, but not both. ${ }^{4}$ Second, we present the first experimental analysis of the effect of random benefit sanctions on job acceptance behavior. ${ }^{5}$ In particular, we compare two unemployment benefit systems, where one system has the same benefit every period, while the other has a lottery over a high and a low benefit. In both cases the expected unemployment benefit per period is the same. Finally, this study presents the first attempt to assess the relative importance of unemployment benefits in determining job acceptance as compared to the wage.

We find the following results. First, the ex ante effect (which is hard to estimate using econometric techniques on real world data) turns out to be substantial and often greater than the ex post effect. This means that the outflow out of unemployment is far higher for the lottery scheme. The policy implication is that introducing benefit sanctions can reduce unemployment even when the expected unemployment benefit level is unchanged. Second, we find that observed acceptance probabilities are lower than the theoretically optimal ones for a risk-neutral individual. This suggests that individuals are risk-seeking more than risk-neutral. Moreover, this effect is most pronounced in the treatment with constant unemployment benefit levels. Again this suggests that a system with constant unemployment benefits over time raises unemployment. The combination of a positive ex ante effect with reservation wages that lie above the optimal risk neutral reservation wages can be explained as follows. A rational

\footnotetext{
${ }^{3}$ The optimal reservation wage in our model does decrease in the last few periods of the 100 period game. But, these last few periods can be omitted from the statistical analysis without a serious loss of information.

${ }^{4}$ The advantage of a finite horizon game in the laboratory seems self evident. The advantage of having a constant reservation wage benchmark is two-fold. First, when optimal behavior is constant, we can expect individuals to "learn" much more effectively within the duration of the experiment. Second, the estimates of the job acceptance rates from the sequences of responses are much more reliable, when optimal behavior is constant over time.

${ }^{5}$ We know of no other experimental study on benefit sanctions. No previous study has examined the effects of introducing and varying random search cost. Braunstein and Schotter $(1981,1982)$ study the effect of varying the probability distribution of wages offers. Cox and Oaxaca $(1989,1992)$ study the effect of varying the probability of wage offer arrivals.
} 
decision maker with a utility function that is convex in income (risk seeking) and that features a disutility in case of a sanction (loss aversion) is consistent with the observed behavior. Third, we find that individuals react as predicted to financial incentives in the form of wages offered or unemployment benefits provided.

The set-up of the paper is as follows. In section 2 we present the theoretical model underlying our experiments. Section 3 describes the experimental set-up. Section 4 presents the results of the experiments. Section 5 concludes.

\section{Job search and benefit sanctions - theory}

The job search model that we analyze, is an extension of the simple one-player search games that were presented in the late 1960's and early 1970's. ${ }^{6}$ Using the basic model in discrete time and with a finite horizon $T$, we add the feature that the job search does not end with the first employment contract, but is a recurring problem. The individual in our model lives an entire working life, with stretches of employment and unemployment. In each period $t=1, \ldots, T$ of the hypothetical life time, the individual receives a single job offer. The job offer in period $t$ is a contract that offers a wage $w_{t}$ in each of the periods $t, . ., \min \{t+$ $\bar{\tau}-1, T\}$, where the tenure $\bar{\tau}$ is the duration of the employment unless the game ends before the tenure. We assume that the wage $w_{t}$ is drawn independently from the same distribution every period. We denote the distribution function of this wage distribution by $F(w)$.

At the outset of the game in period 1, the individual is uncommitted, i.e. currently has no job, but has not yet rejected that period's incoming job offer. An individual who accepts the job offer receives the wage $w_{t}$ in every period for the duration of the employment and cannot quit the job or switch to different employment. During the employment phase, the worker is informed of all job offers that arrive, even though these offers cannot be accepted. After the employment phase, as long as the game has not ended, the individual is back in the uncommitted state, i.e. has lost the previously held job, but has not yet rejected the incoming new job offer.

An uncommitted individual who does not accept the incoming job offer receives the full amount of the unemployment benefit for the current period. This is consistent with the practice in most (if not all) OECD countries where the

\footnotetext{
${ }^{6}$ See Lippman and McCall (1976a and 1976b) for overviews.
} 
unemployed receives full benefits for an initial period. However, after rejecting a wage offer, the uncommitted individual becomes unemployed and may face a benefit sanction, that is the individual may receive a low benefit instead of a high benefit.

An unemployed worker is first told whether he will receive the normal unemployment benefit $b^{h}$ or the reduced benefit $b^{l} \leq b^{h}$ in case he does not accept the incoming job offer that period. ${ }^{7}$ The probability of receiving the high benefit equals $p$ and the probability of getting a benefit sanction imposed and receiving a low benefit equals $(1-p)$. This lottery is played out independently in every period before the unemployed individual gets a new job offer. This timing assumption allows us to identify the ex post effect (see below).

In characterizing the optimal decision rule for a risk-neutral individual, we use the following notation. Let $E\left(V_{t}^{u, h}\right)\left[E\left(V_{t}^{u, l}\right)\right]$ denote the expected continuation payoff for a worker who rejects a wage offer in period $t$, knowing that he gets the high [low] benefit level in period $t$. Using backward induction, we start the analysis at period $T$.

At period $T$ a worker with unemployment benefit level $b^{i}(i=h, l)$ should accept any job with $w \geq b^{i}$. Hence his reservation wage and expected pay off in the period equal

$$
\begin{aligned}
\bar{w}_{T}^{i} & =b^{i} \\
E\left(V_{T}^{u, i}\right) & =F\left(\bar{w}_{T}^{i}\right) b^{i}+\left(1-F\left(\bar{w}_{T}^{i}\right)\right) E\left(w \mid w>\bar{w}_{T}^{i}\right)
\end{aligned}
$$

where $i=l, h$ and $E\left(w \mid w>\bar{w}_{T}^{i}\right)$ denotes the expected wage conditional on this wage exceeding the reservation wage $\bar{w}_{T}^{i}$. Now before the individual knows the realization of $b$, his expected pay off in period $T$ equals

$$
E\left(V_{T}^{u}\right)=p E\left(V_{T}^{u, h}\right)+(1-p) E\left(V_{T}^{u, l}\right)
$$

Now we move back to $t=T-1$ where the worker gets unemployment benefit $b^{i}$ if he rejects the job offer. In the latter case, his expected pay off equals

$$
b^{i}+\delta E\left(V_{T}^{u}\right)
$$

where $\delta$ is the discount factor. If he accepts the job, he gets $w(1+\delta)$. Hence

\footnotetext{
${ }^{7}$ A special case here is $b^{l}=b^{h}=b$, that is the case where an unemployed workers receives the same benefit $b$ every period.
} 
his reservation wage and expected payoffs equal

$$
\begin{aligned}
\bar{w}_{T-1}^{i} & =\frac{b^{i}+\delta E\left(V_{T}^{u}\right)}{1+\delta} \\
E\left(V_{T-1}^{u, i}\right) & =F\left(\bar{w}_{T-1}^{i}\right)\left(b^{i}+\delta E\left(V_{T}^{u}\right)\right)+\left(1-F\left(\bar{w}_{T-1}^{i}\right)\right)(1+\delta) E\left(w \mid w>\bar{w}_{T-1}^{i}\right)
\end{aligned}
$$

Before he knows the realization of $b$, the worker's expected pay off equals

$$
E\left(V_{T-1}^{u}\right)=p E\left(V_{T-1}^{u, h}\right)+(1-p) E\left(V_{T-1}^{u, l}\right)
$$

Similarly we find for $\tau \leq \bar{\tau}-1$ that

$$
\begin{aligned}
\bar{w}_{T-\tau}^{i} & =\frac{b^{i}+\delta E\left(V_{T-\tau+1}^{u}\right)}{\sum_{s=0}^{\tau} \delta^{s}} \\
E\left(V_{T-\tau}^{U, i}\right) & =F\left(\bar{w}_{T-\tau}^{i}\right)\left[b^{i}+\delta E\left(V_{T-\tau+1}^{U}\right)\right]+\left(1-F\left(\bar{w}_{T-\tau}^{i}\right)\right)\left(\sum_{s=0}^{\tau} \delta^{s}\right) E\left(w \mid w>\bar{w}_{T-\tau}^{i}\right) \\
E\left(V_{T-\tau}^{u}\right) & =p E\left(V_{T-\tau}^{u, h}\right)+(1-p) E\left(V_{T-\tau}^{u, l}\right)
\end{aligned}
$$

For $\tau \geq \bar{\tau}$ we get an additional effect. If an individual accepts the current job offer, he knows that after $\bar{\tau}$ periods (when his job ends) he will get the high benefit for sure for one period (if he chooses to reject the job offer then). This prospect of receiving $b^{h}$ in $\bar{\tau}$ periods time lowers his reservation wage today. This is a version of Mortensen's (1977) entitlement effect. By accepting a job now, the agent becomes entitled to receiving the high unemployment benefit in the future (with probability 1 ). This makes the unemployed more eager to accept current wage offers. Hence we get the following equations for the reservation wage, the expected value of being unemployed once you know whether you get a sanction or not this period and the expected value of being unemployed before you know whether or not you are sanctioned this period.

$$
\begin{aligned}
\bar{w}_{T-\tau}^{i}= & \frac{b^{i}+\delta E\left(V_{T-\tau+1}^{U}\right)-\delta^{\bar{\tau}} E\left(V_{T-\tau+\bar{\tau}}^{U, h}\right)}{\sum_{s=0}^{\bar{\tau}-1} \delta^{s}} \\
E\left(V_{T-\tau}^{U, i}\right)= & F\left(\bar{w}_{T-\tau}^{i}\right)\left[b^{i}+\delta E\left(V_{T-\tau+1}^{U}\right)\right]+ \\
& +\left(1-F\left(\bar{w}_{T-\tau}^{i}\right)\right)\left[\left(\sum_{s=0}^{\bar{\tau}-1} \delta^{s}\right) E\left(w \mid w>\bar{w}_{T-\tau}^{i}\right)+\delta^{\bar{\tau}} E\left(V_{T-\tau+4}^{U, h}\right)\right] \\
E\left(V_{T-\tau}^{u}\right)= & p E\left(V_{T-\tau}^{u, h}\right)+(1-p) E\left(V_{T-\tau}^{u, l}\right)
\end{aligned}
$$

Using these equations we can derive the optimal decision rules for riskneutral agents in our experiment. First, we describe the experimental set up. 


\section{Experimental setup}

Our experiment consists of three random benefit sanction treatments and a sure benefit control treatment. The sanction probability (i.e. the probability of a benefit reduction $1-p$ ) equals 0.4 in the three corresponding treatments. The expected value of the unemployment benefit is constant across all four treatments, but the (mean preserving) spread is increased systematically. Table 1 summarizes the parameters of our treatments.

Table 1 - Experimental treatments

\begin{tabular}{cccccc}
\hline treatment & $\begin{array}{c}\text { full } \\
\text { benefit }\end{array}$ & $\begin{array}{c}\text { reduced } \\
\text { benefit }\end{array}$ & $\begin{array}{c}\text { sanction } \\
\text { probability }\end{array}$ & $\begin{array}{c}\text { EV } \\
\text { of benefit }\end{array}$ & $\begin{array}{c}\text { number of } \\
\text { participants }\end{array}$ \\
\hline no spread & 60 & - & - & 60 & 15 \\
spread 25 & 70 & 45 & 0.4 & 60 & 15 \\
spread 50 & 80 & 30 & 0.4 & 60 & 16 \\
spread 75 & 90 & 15 & 0.4 & 60 & 16 \\
\hline
\end{tabular}

A total of 62 individuals participated in the experiment, with 16 participants in the "spread 75" and "spread 50" treatments and 15 participants in the other two treatments. All treatments were run on the same day at the CentERlab, Tilburg University with software based on the experimental software toolbox RatImage (Abbink and Sadrieh 1995). As the participants randomly arrived at the location, they were assigned to one of the four treatments in an alternating sequence. This guaranteed the randomization of participants across treatments with almost equal numbers in each treatment.

Upon arrival, each participant was seated in a cubical and received written instructions (see the appendix). If there were any questions, these were answered privately at the cubicle. Each participant played a single 100-period job search game. The participants could leave the laboratory as soon as they had completed their task. Including the time for waiting and reading the instructions, no one needed more than one hour for participation.

All participants were undergraduate economics students in their second year and the experiment was part of their labor economics course. Instead of providing financial incentives, we provided the students with the possibility to "earn" about 20 percent of their course grade by participating in the experiment. The higher a participant's absolute score in the experiment, the better was the grade received. The grading scheme was known to the students from the outset of the experiment and the instructions (see the appendix) included a table translating 
scores into grades. ${ }^{8}$ The incentive compatible grading of student participants is a well-established method in experimental economics. ${ }^{9}$

For each of the treatments we have derived the optimal decision rules using the reservation wages in the previous section. The parameter values are as follows. The tenure length equals $\bar{\tau}=4$, the discount factor $\delta=1$ and the wage distribution is assumed to be uniform on the interval [90,200]. For the no spread treatment we have $b^{h}=b^{l}=60$, for the spread 25 treatment we have $b^{h}=70, b^{l}=45$, for the spread 50 treatment we have $b^{h}=80, b^{l}=30$ and for the spread 75 treatment we have $b^{h}=90, b^{l}=15$. In each case the probability of receiving the high benefit equals $p=0.6$.

As indicated in the theoretical section the optimal reservation wage is conditional on the realization of the unemployment benefit in the current period. Figure 1 shows for various unemployment benefits the relationship between the optimal reservation wage $(r w)$ and the stage of the game (rw15 denotes the reservation wage when the individual's unemployment benefit equals 15 in that period, etc.). Given a specific level of the unemployment benefit, the optimal reservation wage is basically constant for most part of the game, only declining sharply towards the benefit level in the last couple of rounds. Hence, the optimal reservation wage provides a simple benchmark for the analysis of the observed behavior.

Over the range where reservation wages are constant (roughly, period 1 to 90) we find the following values: $r w 15=117.2$, $r w 30=121.0, r w 45=124.9$, $r w 60=128.9, r w 70=131.2, r w 80=133.5$ and $r w 90=136.0$. With the assumed uniform distribution of wage offers on $[90,200]$ we can translate the reservation wages into probabilities to accept a job offer, $\pi=\frac{200-r w}{200-90}$. Table 2 shows these probabilities in the first two columns.

\footnotetext{
${ }^{8}$ The score table we used was based on the optimal reservation wage strategy for riskneutral individuals. Since these strategies lead to expected payoffs of about 150 to 155 per period in all treatments, we used the same score table for all participants.

${ }^{9}$ Two examples of the grade payment experiments can be found in Selten, Mitzkewitz, and Uhlich (1997) and Selten, Abbink, Buchta, and Sadrieh (2003). See Friedman and Sunder (1994) for a discussion of the method.
} 
Table 2 - Optimal job acceptance probabilities $\pi *$

\begin{tabular}{cccccc}
\hline treatment & $\begin{array}{c}\text { full } \\
\text { benefit }\end{array}$ & $\begin{array}{c}\text { reduced } \\
\text { benefit }\end{array}$ & $\begin{array}{c}\text { unconditional } \\
\text { probability } \pi\end{array}$ & $\begin{array}{c}\text { ex ante } \\
\text { effect }\end{array}$ & $\begin{array}{c}\text { ex post } \\
\text { effect }\end{array}$ \\
\hline no spread & - & - & .65 & .00 & - \\
spread 25 & .63 & .68 & .65 & .00 & .05 \\
spread 50 & .60 & .72 & .65 & .00 & .12 \\
spread 75 & .58 & .75 & .65 & .00 & .17 \\
\hline
\end{tabular}

*) Optimal in all periods in which the optimal reservation wage is constant.

So conditional on having a low benefit in the spread 25 treatment, the probability of accepting a job equals .68, etc. The unconditional probability of accepting a job in the spread 25 treatment equals $.6 * .63+.4 * .68=.65$ (where $p=.6$ equals the probability of receiving the high benefit). We define the ex ante effect of benefit sanctions as the difference between the unconditional acceptance probability under a positive spread treatment and the acceptance probability under the no spread treatment. The idea is that the expected benefit is the same under both treatments ${ }^{10}$ and hence the acceptance probabilities can be meaningfully compared.

In the theoretical outcome with risk-neutral agents, the ex ante effect turns out to be zero. The higher reservation wage (compared to the no spread reservation wage) at the high unemployment benefit cancels the lower reservation wage at the low unemployment benefit. Hence, theoretically, we find no effect on the job acceptance rate of increasing the spread (for a given expected unemployment benefit level). This result crucially depends on the assumption of risk neutrality. The ex ante effect, for example, will be strictly positive, if we assume that the individuals weigh losses higher than gains of the same magnitude (in the spirit of Kahneman and Tversky (1979)). Clearly, risk aversion instead of loss aversion will also lead to a positive ex ante effect. However, as described later, we find that the participants in our experiment exhibit behavior that seems more in line with a loss aversion model than with a fixed risk attitude model.

The ex post effect is the difference between the acceptance probability before and after the sanction is imposed. It is reported in the fifth column of table 2. This effect is positive and increasing in the spread. This is what we find in the

\footnotetext{
${ }^{10}$ Strictly speaking this is not true since the individual always receives the high benefit for sure in the first period after an employment spell. Taking this into account would make the theoretical ex ante effect slightly negative. Our observations, however, show that the effect is in fact positive.
} 
experiment as well.

\section{Results}

\subsection{Non-parametric tests}

Reservation wage choices are not directly observable. We, therefore, will concentrate on observed acceptance rates for most of our data analysis. Instead of using the data of all 100 rounds of play, we restrict our analysis to the acceptance rates in the rounds 11 to 90 . We drop the first 10 rounds from the analysis, because experiment participants generally need some time (i.e. some rounds of play) before they have adapted to the experimental decision situation. We drop the last 10 rounds from the analysis, because optimal acceptance probabilities increase in the last 5 to 10 periods of our finite search game.

Table 3 displays the mean observed acceptance rates of the individuals in our experiment for each of the possible levels of unemployment benefits. Note that these acceptance rates could only be computed for those participants, who both accepted and rejected at least one wage offer at the given level of unemployment benefit. For this reason, table 2 also includes a line displaying the number of individuals that could be included in each of the calculations.

Remember that when an individual is committed (i.e. is on a job and the tenure has not ended), this individual cannot accept a new wage offer. Therefore, the job acceptance rate is defined as the ratio of accepted wage offers to all received offers in uncommitted periods (i.e. the sum of accepted plus rejected wage offers). As a benchmark we consider the conditionally optimal acceptance rate for each individual: For each period $t$ in which the individual was free to accept or to reject the received wage offer (i.e. the individual was not committed), we compare the wage offer to the optimal reservation wage at the given benefit level for a game starting in $t$ and lasting another $T-t$ periods. ${ }^{11}$ The acceptance rates are calculated both including and excluding the first periods

\footnotetext{
${ }^{11}$ This is conditionally optimal in the following sense. Given that the individual has a choice at time $t$, we assume that optimal choices are made from $t$ onwards, no matter whether the decisions before period $t$ were optimal or not. Note that if the individual had followed a fully optimal decision path, he may have been committed in $t$ and not have had the choice he is given under conditional optimality. In this manner, conditional optimality provides us with a rational benchmark that allows for non-optimal histories of play and is, thus, better comparable to the observed behavior than the fully optimal decision path.
} 
after an employment spell. Table 3 displays the observed mean acceptance frequencies for each of the possible levels of unemployment benefits together with the conditionally optimal risk-neutral acceptance rates.

Obviously, the optimal acceptance rate decreases monotonically with the benefit level (see table 2), because the opportunity cost of waiting for a better job offer next period is lower when benefits are lower. The fact that the conditionally optimal rates shown in table 3 do not perfectly follow this pattern is due to the different realizations of the stochastic variables. To avoid misinterpretations based on the differences in the realizations, we compare the differences of the mean observed to the conditionally rational acceptance rates across benefit levels.

\section{Table 3 - Observed and conditionally optimal acceptance rates}

\begin{tabular}{lrrrrrrr}
\hline benefit level & 15 & 30 & 45 & 60 & 70 & 80 & 90 \\
\hline \multicolumn{5}{c}{ all periods in which an } & offer & could have been accepted \\
conditionally optimal rate & .69 & .71 & .75 & .67 & .66 & .60 & .60 \\
& & & & & & & \\
mean observed rate & .60 & .57 & .64 & .50 & .53 & .57 & .56 \\
observed SD & .16 & .16 & .11 & .08 & .11 & .12 & .15 \\
number of individuals & 12 & 11 & 15 & 15 & 15 & 16 & 16 \\
& & & & & & & \\
observed - optimal & -.08 & -.14 & -.11 & -.18 & -.13 & -.04 & -.04 \\
significance level* & .05 & .05 & .05 & .001 & .001 & n.s. & n.s.
\end{tabular}

excluding the first period after each employment

\begin{tabular}{lrrrrrrr} 
conditionally optimal rate & .69 & .71 & .75 & .67 & .68 & .62 & .69 \\
& & & & & & & \\
mean observed rate & .60 & .57 & .64 & .50 & .61 & .57 & .64 \\
observed SD & .16 & .16 & .11 & .08 & .08 & .15 & .10 \\
number of individuals & 12 & 11 & 15 & 15 & 13 & 13 & 14 \\
& & & & & & & \\
& -.08 & -.14 & -.11 & -.18 & -.08 & -.04 & -.05 \\
observed - optimal rate & .05 & .05 & .05 & .001 & .05 & .10 & .05 \\
significance level* & .05 & *) Wilcoxon signed-ranks test, one-tailed. ("n.s." = "not significant at .10") & \\
\hline
\end{tabular}

Comparing the optimal to the observed acceptance rates in the top part of table 3, we find that in all seven cases, the mean observed acceptance rate is 
smaller than the conditionally optimal rate. The differences, however, are not significant for the two highest levels. It seems that observed behavior is closest to the conditionally optimal benchmark in the cases with high benefits, while it is furthest away in the case with no benefit sanctions.

Since there is no benefit sanction in a period immediately following employment, the results may be affected in a systematic way by including those periods. But, as the lower part of table 3 shows, our main observations remain basically unchanged when we calculate the acceptance rates excluding the first period after each employment phase. ${ }^{12}$ Excluding the first period after employment, the differences between the observed and conditionally optimal acceptance rates slightly increase for the two highest benefit levels, making the difference significant for the benefit level 90 and weakly significant for the benefit level 80 . Additionally, the mean acceptance rate in the case of the benefit of 70 moves down, closer to the conditionally optimal rate.

Although the observed acceptance rates in all high benefit settings (70, 80, 90) are closer to the conditionally optimal rates than in the corresponding low benefit settings $(45,30,15)$, the difference is only significant in the spread 50 treatment, i.e. when comparing the benefit 80 to the benefit 30 setting. Comparing the six benefit sanction settings to the no sanction treatment (with a benefit level of 60 ), we find no significant differences between the low benefit and the no sanction settings, but significant differences between the high benefit and the no sanction settings.

Table 4 shows the mean optimal and mean observed acceptance rates aggregated over both benefit levels of each benefit sanction treatment. The conditionally optimal acceptance rate is $12 \%$ greater than the aggregate observed level in the spread 25 treatment. It is $8 \%$ greater in the spread 50 and $7 \%$ greater in the spread 75 treatment. Although the observed acceptance levels are too low compared to the corresponding optimal level in all three cases, this distance is significantly smaller in the benefit sanction treatments than it is with fixed benefits of 60 . The fact that the aggregate rate of acceptance is significantly closer to optimum in the benefit sanction treatments indicates that there is a positive ex ante effect of introducing benefit sanctions. The one to the last column of table 4 shows the difference in differences (between observed and optimal ac-

\footnotetext{
${ }^{12}$ Notice that there can be no difference between the top and the bottom half of table 3 for the low benefit levels $(15,30,45)$, because these benefit levels do not occur immediately following employment.
} 
ceptance rates) as a measure of the ex ante effect. Put differently, it compares the observed ex ante effect with the conditionally optimal ex ante effect (which is not equal to zero $)^{13}$. The ex ante effect is positive in all cases. It appears especially significant and strong ( $8 \%-11 \%)$ when we consider only those periods in which a benefit sanction was possible.

Furthermore, the levels of the ex ante effect displayed in table 4 seem to increase with the spread. This increase, however, is rather small and in most cases insignificant. Testing the difference in differences across treatments with the Mann-Whitney U-test, we find a significant difference only between the spread 25 and the spread 50 treatment when all periods are taken into consideration. When only the periods are taken into consideration in which benefit sanctions were possible, no significant differences can be found between the sanction treatments concerning the ex ante effect. So we conclude that a substantial ex ante effect exists that is not very sensitive to the size of the benefit sanction.

Table 4 - Job acceptance rates and the ex ante effect

\begin{tabular}{lccccc}
\hline treatment & $\begin{array}{c}\text { mean } \\
\text { observed rate }\end{array}$ & $\begin{array}{c}\text { conditionally } \\
\text { optimal rate }\end{array}$ & difference & $\begin{array}{c}\text { ex ante } \\
\text { effect }\end{array}$ & $\begin{array}{c}\text { significance } \\
\text { level* }\end{array}$ \\
\hline no spread & .50 & .67 & -.18 & - & - \\
& & all periods in which an offer could have been accepted \\
spread 25 & .59 & .70 & -.12 & .06 & .10 \\
spread 50 & .57 & .65 & -.08 & .10 & .01 \\
spread 75 & .58 & .64 & -.07 & .11 & .05 \\
& & excluding the first period after each employment \\
spread 25 & .63 & .72 & -.09 & .08 & .01 \\
spread 50 & .57 & .66 & -.09 & .09 & .05 \\
spread 75 & .62 & .69 & -.07 & .11 & .01 \\
\hline *) Comparing the distributions of the acceptance rate differences to the no spread \\
treatment with the Mann-Whitney U-test, one-tailed. ("n.s." = "not significant at .10") \\
\hline
\end{tabular}

A simple model of loss aversion organizes our observations well. Following Kahneman and Tversky (1979), we assume that individuals weigh losses higher than they weigh gains of the same magnitude. ${ }^{14}$ If we interpret the randomly

\footnotetext{
${ }^{13}$ Recall that the ex ante effect in table 2 (which is equal to zero) is calculated as an expectation over wages. The conditionally optimal ex ante effect in table 4 is calculated for the particular wage sequence used in the experiment.

${ }^{14}$ This has been found to hold true in a number of settings. For an overview see Camerer (1995).
} 
imposed benefit sanction as a loss, then the expected utility of loss averse individuals from a fixed benefit may be greater than their expected utility from an uncertain benefit with the same expected value. Note that, due to loss aversion, this can be true even if the individual is risk-seeking. An example of the utility function we have in mind is

$$
u(x)=\left\{\begin{array}{ccc}
x^{\alpha} & \text { if } & x \geq 60 \\
x^{\alpha}-\ell & \text { if } & x<60
\end{array}\right.
$$

with $\alpha>1$ and $\ell>0$.

Here we see that because of $\alpha>1$ the individual is risk-seeking, i.e. will exhibit a lower job acceptance rate than a risk-neutral individual would. At the same time, however, our model decision-maker - being loss-averse - will exhibit a lower rate of acceptance in the safe setting (without benefit sanctions) than in a risky setting (with benefit sanctions) that provides the same expected benefit. This is because the expected utility of the risky benefit is smaller than the utility of the safe benefit, due to the disutility of experiencing a loss, i.e. due to $\ell>0 .{ }^{15}$ Hence, this simple model captures both of our main observations:

- Observation 1) The experimentally observed rate of job offer acceptance is generally smaller than the optimal risk-neutral rate.

- Observation 2) The experimentally observed rate of job offer acceptance comes significantly closer to the optimal risk-neutral rate when benefit sanctions are introduced.

\subsection{Parametric analysis}

Observing the behavior of 62 individuals over 100 time periods generates 6200 observations. However, in many periods the individuals do not have a choice because they have a job from which they are not allowed to quit. And, as in the previous subsection we base the analysis on the behavior of individuals from period 10 to 90 . This leaves us with 1928 observations relevant for an analysis of unemployment behavior because they concern periods in which the individual

\footnotetext{
${ }^{15}$ The model can be extended to allow the disutility of experiencing a loss to depend on the size of the loss. This would explain why the acceptance rates in the high spread benefit sanction treatments are somewhat lower than in the spread 25 treatment. Note, however, that the observed differences of acceptance behavior across the benefit sanction treatments are not statistically significant.
} 
decides on whether or not to accept a wage offer. In total there are 871 rejections of wage offers and 1057 acceptations. Of the 1928 observations 1057 refer to the first period after unemployment (or the first period of the game) during which the individual is not liable for a benefit sanction. The remaining 871 observations concern periods when the individual was potentially confronted with a benefit sanction.

For the parametric analysis of the behavior of the participants in the experiments we use the fixed effects logit model

$$
\operatorname{Pr}\left(y_{i t}=1\right)=\frac{e^{\alpha_{i}+\beta x_{i t}}}{1+e^{\alpha_{i}+\beta x_{i t}}}
$$

where $y$ equals $1(0)$ if a wage offer is accepted (rejected), $i$ refers to participant $(1, \ldots, 62), t$ refers to the period $(11, \ldots, 90)$. Furthermore, $x$ is a vector of explanatory variables, the $\alpha_{i}$ represent individual fixed effects and $\beta$ is a vector of parameters. The explanatory variables are the wage offer (wage), unemployment benefits (benefits) and the period of the game (time). The parameters of the fixed effects logit model are estimated using Chamberlain's conditional likelihood method. The results are shown in Table 5.

Table 5 - Parameter estimates fixed effects logit model ${ }^{*)}$

\begin{tabular}{|c|c|c|c|c|}
\hline & \multicolumn{2}{|c|}{ Potential sanction period } & First period $\left.^{a}\right)$ & All \\
\hline & (1) & $(2)$ & $(3)$ & $(4)$ \\
\hline Wage & $0.157(11.1)$ & $0.159(11.3)$ & $0.156(13.0)$ & $0.152(19.1)$ \\
\hline Benefit & $-0.040(5.5)$ & $-0.039(5.5)$ & - & $-0.045(9.1)$ \\
\hline Time & $-0.005(0.6)$ & - & - & - \\
\hline Hausman $\chi^{2}$ & 18.3 & 17.8 & 34.8 & 104.2 \\
\hline \multirow[t]{2}{*}{-Loglikelihood } & 102.3 & 102.4 & 135.6 & 304.4 \\
\hline & \multicolumn{2}{|c|}{871} & 1057 & 1928 \\
\hline
\end{tabular}

a) In the first period after job loss the unemployed is not liable for a sanction

*) absolute t-values in parentheses

The first column shows the parameters for the potential sanction periods. It is clear that conditional on differences between individuals, high wage offers have a positive effect and high benefits have a negative effect on the acceptance probability. Time does not seem to affect the acceptance probability. Apparently individuals do not change their behavior over the game, which is in line with the theoretical section where it was shown that the optimal reservation wage is approximately constant between periods 1 and 90 . The $\chi^{2}-$ statistic 
of the Hausman test for homogeneity $\left(\alpha_{i}=\alpha\right)$ indicates that we cannot accept the absence of heterogeneity in the intercepts. ${ }^{16}$ The second column of Table 5 shows the parameter estimates if we omit time as an explanatory variable. Indeed, the parameter estimates hardly change. The third column shows the estimation results if we use the information collected in the first period after unemployment when individuals were never confronted with a benefit reduction. Then, since the benefits are always the same, we cannot identify the benefit effect because this is absorbed by the individual fixed effects. The estimated wage effect is almost the same as the one shown in the second column of Table 5. Finally, the fourth column shows the parameter estimates if we pool across periods. ${ }^{17}$ In all estimates we find that the effect of a change in the wage is at least three times as big as the effect of a change in the benefit level. This is surprising as one would expect that $w-b$ is a reasonable approximation of the relevant decision margin. Perhaps individuals use $w-E(b)$ as decision margin in which case the particular realization of $b$ is not so relevant and hence yields only small effect.

Because from the first period after unemployment we cannot derive information about (ex post) sanction effects we focus the remaining analysis on the periods when individuals were sometimes exposed to benefit sanctions. To check the robustness of our parameter estimates we split-up the sample according to the four groups of treatments and estimated the fixed effects logit model for each of the groups separately. The results are shown in Table 6 .

${ }^{16}$ The Hausman tests compares Chamberlain's conditional maximum likelihood estimator (CMLE) and the usual maximum likelihood estimator of the binomial logit (ML). $\mathrm{H}_{0}$ is that the difference in coefficients is not systematic and is based on the chi-squared statistic (See Greene, 2000):

$$
\chi^{2}=\left(\widehat{\beta}_{C M L}-\widehat{\beta}_{M L}\right)^{\prime}(\operatorname{Var}[C M L]-\operatorname{Var}[M L])^{-1}\left(\widehat{\beta}_{C M L}-\widehat{\beta}_{M L}\right)
$$

The critical $\chi^{2}$-value ( $5 \%$ level) for 3 degrees of freedom is equal to 7.8 , for 2 degrees this is 6.0 , for 1 degree of freedom it's 3.84 .

${ }^{17}$ The likelihood-ratio statistic for pooling across the different periods equals 132.8 , indicating that pooling across the first periods and later periods is not allowed. 
Table 6 - Parameter estimates fixed effects logit model - subgroups*)

\begin{tabular}{l|cccc}
\hline & Spread0 & Spread25 & Spread50 & Spread75 \\
\hline Wage & $0.164(6.1)$ & $0.174(5.0)$ & $0.152(5.3)$ & $0.155(5.7)$ \\
Benefit & - & $-0.078(2.6)$ & $-0.045(3.2)$ & $-0.032(3.3)$ \\
- Loglikelihood & 29.7 & 20.0 & 25.4 & 25.7 \\
Hausman $\chi^{2}$ & 3.5 & 1.4 & 5.4 & 6.5 \\
\multicolumn{1}{c}{$N$} & 251 & 204 & 200 & 216 \\
\hline
\end{tabular}

*) absolute t-values in parentheses

For all groups we again find that a higher wage offer increases the probability of acceptance. And for groups with non-constant benefits we again find a negative effect of the benefit level. A Likelihood ratio test for the restriction that the parameter estimates of all explanatory variables are the same across the four groups equals 3.20. Since at a $5 \%$ significance level the critical $\chi^{2}$ with 5 degrees of freedom equals 11.1 we cannot reject the hypothesis that conditional on the fixed effects the parameters are the same for every group in the sample. Or, in other words if we allow for individual fixed effects pooling across the four groups is allowed. For the first three groups in Table 6 the Hausman tests indicate that the hypothesis of no heterogeneity in the intercepts cannot be rejected. For the fourth group the Hausman test is only insignificant at a $10 \%$ level. Nevertheless these results in comparison to those in Table 5 suggest that within the separate groups intercepts are the same while between groups the intercepts are different.

Our estimation results clearly indicate that individuals respond to financial incentives, both through the wage offer and the benefit reduction. The parameter estimates concerning the benefits refer to the so called ex post effect. Once a benefit is reduced the individual is more likely to accept a wage offer. In the set-up of the experiment it is possible to investigate the ex post effect for each of the individuals participating in the experiment. We are also interested in the so called ex ante effect. This is the effect that individuals that are confronted with the possibility of benefit reduction will already change their behavior even before this reduction is actually imposed. To get an idea of this effect we have to compare behavior across individuals because the same individual was not exposed to different sanction regimes. Therefore, if there is an ex ante effect this is picked up by the fixed effects. In order to identify the ex ante effect we have to compare the behavior of individuals from different groups correcting for the effects of wages and benefits. Since we do not find (a lot of) heterogeneity 
in the intercept of the logit model for the separate groups the identification of the ex ante effect is straightforward. Using a binomial logit model we establish whether conditional on wages and benefits there is a difference between the four groups. If there is, this is due to the ex ante effect.

Columns 1 to 4 of Table 7 show the parameter estimates of the binomial logit model for the four groups of individuals. Column 5 shows the parameter estimates if we would simply pool across the four groups and ignore the ex ante effect. The value of the LR-test is equal to 12.3 which indicates that we cannot simply pool across the four groups. Column 6 shows the parameter estimates if we allow the intercept to differ between the groups by introducing dummy variables for the three groups with a positive spread in benefits.

Table 7 - Parameter estimates binomial logit model ${ }^{*)}$

\begin{tabular}{l|cccc}
\hline & $(1)$ & $(2)$ & $(3)$ & $(4)$ \\
\hline & Spread0 & Spread25 & Spread50 & Spread75 \\
\hline Wage & $0.125(7.2)$ & $0.147(6.1)$ & $0.104(6.8)$ & $0.098(7.1)$ \\
Benefit & - & $-0.058(2.4)$ & $-0.023(2.2)$ & $-0.015(2.4)$ \\
- Loglikelihood & 63.9 & 46.6 & 62.3 & 69.3 \\
\multicolumn{1}{c}{$N$} & 251 & 204 & 200 & 216 \\
\hline
\end{tabular}

\begin{tabular}{l|ccc}
\hline & $(5)$ & $(6)$ & $(7)$ \\
\hline Wage & $0.111(13.8)$ & $0.115(13.8)$ & $0.114(13.7)$ \\
Benefit & $-0.023(4.4)$ & $-0.022(4.2)$ & $-0.022(4.2)$ \\
Spread $=25$ & - & $1.02(3.1)$ & - \\
Spread $=50$ & - & $1.24(3.8)$ & - \\
Spread $=75$ & - & $0.96(3.0)$ & - \\
Spread $>0$ & - & - & $1.07(4.1)$ \\
- Loglikelihood & 254.4 & 245.1 & 245.5 \\
\multicolumn{1}{c}{$N$} & & 871 & \\
\hline
\end{tabular}

*) t-values in parentheses

Indeed, conditional on benefits and wage offer those that are subject to possible benefit sanctions have a higher acceptance probability than the reference group. This represents the ex ante effect. The seventh column of Table 7 shows the parameter estimates if we impose the ex ante effect to be the same across all groups. As shown the estimation results hardly change so we cannot reject 
the hypothesis that the ex ante effect is constant across the three groups. ${ }^{18}$

To give an impression about the size of the effects we use the parameters in the seventh column of Table 7 to perform some simulations of which the results are shown in Table 8.

Table 8 - Simulation results; acceptance probabilities in $\%^{*}$ )

\begin{tabular}{c|c|ccc|cc|cc|cc}
\hline Spread & 0 & \multicolumn{2}{|c|}{25} & avg. & \multicolumn{2}{|c|}{25} & \multicolumn{2}{|c|}{50} & \multicolumn{2}{|c}{75} \\
\hline benefit & 60 & 70 & 45 & 60 & ex post & ex ante & ex post & ex ante & ex post & ex ante \\
\hline Wage & $(1)$ & $(2)$ & $(3)$ & $(4)^{a)}$ & $(3)-(2)$ & $(4)-(1)$ & & & & \\
\hline 125 & 9.4 & 19.5 & 29.5 & 23.5 & 10.0 & 14.1 & 20.6 & 15.1 & 31.3 & 16.6 \\
150 & 64.1 & 80.7 & 87.9 & 83.6 & 7.2 & 19.5 & 13.9 & 18.5 & 20.4 & 17.0 \\
175 & 96.9 & 98.6 & 99.2 & 98.9 & 0.6 & 2.0 & 1.1 & 1.9 & 1.7 & 1.7 \\
\hline
\end{tabular}

*) based on the parameter estimates of table 7 , column 3

a) $0.6^{*}(2)+0.4^{*}(3)$

Table 8 shows that with a wage offer of 125 and fixed benefits of 60 the acceptance probability is equal to $9.4 \%$. With benefits of 70 but in a situation where the individual may be confronted with a benefit sanction later on the acceptance probability would be $19.5 \%$. The fact that this acceptance probability is higher than with a fixed benefit of 60 is due to the fact that the ex post effect is smaller than the ex ante effect. With benefits of 45 the acceptance probability is $29.5 \%$. The difference between $29.5 \%$ and $19.5 \%$ is due to the ex post effect of a benefit sanction. The weighted average acceptance probability for a 45-70 combination is $23.5 \%$. The difference between $23.5 \%$ - with an expected benefit level of 60 - and $9.4 \%$ - with a fixed benefit level of 60 - is the ex ante effect, equal to $14.1 \%$.

Table 8 shows calculated ex post effects and ex ante effects for other combinations of wage offers and benefit levels. For example if the wage offer increases to 150 the ex post effect declines to $7.2 \%$ while the ex ante effect increase to $19.5 \%$. The ex post effect is smaller because the acceptance probability with a high benefit is already as high as $80.7 \%$. If the wage offer is equal to 175 the ex post effect is equal to $0.6 \%$ and the ex ante effect is equal to $2.0 \%$. Both effects are small because the acceptance probability is high irrespective of the (expected) benefit level.

\footnotetext{
${ }^{18}$ The LR test statistic is equal to 0.3 , the critical $\chi^{2}-$ value $=6.0$. Note that pooling across the four groups is allowed once we account for the ex ante effect. The LR test statistic is 6.8 , the critical $\chi^{2}-$ value $=7.8$.
} 
Table 8 also shows ex post effects and ex ante effects for other combinations of benefit levels that have the same expected benefit of 60 . Of course if the spread increases the ex post effect increases as well. At low wage levels, where acceptance probabilities are low the ex ante effect increases with the spread. At higher wage levels and low benefit levels the acceptance probabilities are close to 1 and therefore the ex ante effect decreases with the spread in the benefit levels.

\section{Conclusions}

In this paper we analyze job search behavior in the presence of unemployment benefits and unemployment benefit sanctions. Our analysis is based on laboratory experiments in which the arrival of job offers is exogenous. We focus on wage offer acceptance behavior. In theory the job search behavior of an unemployed worker is influenced by a system of benefit sanctions in two distinct ways. First, if an unemployed worker is confronted with a benefit sanction, a reduction of the benefits, a worker will be more likely to accept a given job offer. This is the so called ex post effect. Second, to avoid being confronted with a benefit sanction a worker will be more likely to accept a given wage offer than he would be if his benefits would be constant and no system of benefit sanctions existed. This is the so called ex ante effect.

Our experiments show that both ex post effect and ex ante effect are relevant. The magnitude of both effects depends on the structure of the system of benefit sanctions and on the specific wage offers. In most cases the ex ante effect (which is hard to estimate using econometric techniques on real world data) is larger than the ex post effect. In the experiment we compare two unemployment benefit systems where one system has the same benefit every period and the other a lottery over a high and a low benefit. In both cases the expected unemployment benefit per period is the same. Then we find that the outflow out of unemployment is far higher for the lottery scheme. The policy implication is that introducing benefit sanctions can reduce unemployment even when the expected unemployment benefit level is unchanged.

We also find that reservation wages are higher than the theoretically optimal ones for a risk-neutral individual. This effect is most pronounced in the treatment with constant unemployment benefit levels. Again this suggests that a system with constant unemployment benefits over time raises unemployment. 
The combination of risk seeking behavior with respect to job acceptance probabilities and a positive ex ante effect can be explained in a rational model where the utility function is convex in income and features loss aversion. 


\section{Appendix: Instructions}

\subsection{The "no spread" treatment}

Department of Economics, Tilburg University

330071: Sociaal economisch beleid

\section{Instructions for the Job Search Experiment}

Welcome to our job search experiment!

Please, read these instructions carefully. If you should have any questions, please, raise your hand and wait for an experimenter to come to your cubicle. Once you have completed the experiment, you may leave the laboratory.

Please, remain quite and do not communicate with the other participants.

The decision task you face in this experiment resembles job market decision making, but is simplified in a number of ways. Thus, although job market terminology is used, you are asked to focus only on the decisions and payoffs that are actually part of the experimental setting. Your goal in the experiment should be to maximize payoffs.

The experiment consists of 100 rounds.

In each round, you are offered a contract to work for 4 consecutive rounds at a specified wage.

The offered wage is always in the range of (and including) 90 to 200 Taler, where Taler is the name of the experimental currency unit.

If you accept the job offer, you will receive the offered wage in the current round and in each of the next 3 rounds. You cannot break the contract and quit the job prematurely. To be able to accept a different job offer, you will have to wait until the employment has terminated. The duration of employment is displayed on your screen in the field labeled "Tenure". It remains constant throughout the entire experiment. If you reject a job offer, you will receive an unemployment benefit in the current round and will be free to accept or reject the job offer in the next round. The amount of unemployment benefit that you will receive is 60 Taler.

After the experiment, the part of your course grade that depends on this experiment will be determined as follows:

\begin{tabular}{|c|c|c|c|c|c|c|c|c|c|c|}
\hline $\begin{array}{c}\text { average } \\
\text { payoff }\end{array}$ & $0-14$ & $15-29$ & $30-44$ & $45-59$ & $60-74$ & $75-89$ & $90-104$ & $105-119$ & $120-134$ & $>135$ \\
\hline grade & 1 & 2 & 3 & 4 & 5 & 6 & 7 & 8 & 9 & 10 \\
\hline
\end{tabular}

Thank you for participating. 


\title{
6.2 Instructions for the "spread 25 " treatment ${ }^{19}$
}

\author{
Department of Economics, Tilburg University
}

330071: Sociaal economisch beleid

\section{Instructions for the Job Search Experiment}

Welcome to our job search experiment!

Please, read these instructions carefully. If you should have any questions, please, raise your hand and wait for an experimenter to come to your cubicle. Once you have completed the experiment, you may leave the laboratory.

Please, remain quite and do not communicate with the other participants.

The decision task you face in this experiment resembles job market decision making, but is simplified in a number of ways. Thus, although job market terminology is used, you are asked to focus only on the decisions and payoffs that are actually part of the experimental setting. Your goal in the experiment should be to maximize payoffs. The experiment consists of 100 rounds. In each round, you are offered a contract to work for 4 consecutive rounds at a specified wage. The offered wage is always in the range of (and including) 90 to 200 Taler, where Taler is the name of the experimental currency unit.

If you accept the job offer, you will receive the offered wage in the current round and in each of the next 3 rounds. You cannot break the contract and quit the job prematurely. To be able to accept a different job offer, you will have to wait until the employment has terminated. The duration of employment is displayed on your screen in the field labeled "Tenure". It remains constant throughout the entire experiment. If you reject a job offer, you will receive an unemployment benefit in the current round and will be free to accept or reject the job offer in the next round. The amount of unemployment benefit that you will receive may be "full" or "reduced". The full benefit is 70 Taler, while the reduced benefit is 45 Taler.

You are certain to receive the full unemployment benefit when you are unemployed - in the very first round of the experiment

- in any first round of unemployment immediately following a round of employment.

In all other rounds, there will be a lottery determining whether you will receive the full or the reduced benefit. The probability of receiving the full benefit is $60 \%$ and the probability of receiving the reduced benefit is $40 \%$. The lottery takes place at the

${ }^{19}$ The "spread 50" and "spread 75 " treatments are similar. Replace "70" by "80" and "45" by " 30 " for spread 50 treatment. Replace " 70 " by " 90 " and " 45 " by " 15 " for the spread 75 treatment. 
beginning of the round, which means that you will know the outcome of the lottery before you make a decision on the current job offer. All parameters concerning the unemployment benefit remain constant throughout the entire experiment.

After the experiment, the part of your course grade that depends on this experiment will be determined as follows:

\begin{tabular}{|c|c|c|c|c|c|c|c|c|c|c|}
\hline $\begin{array}{c}\text { average } \\
\text { payoff }\end{array}$ & $0-14$ & $15-29$ & $30-44$ & $45-59$ & $60-74$ & $75-89$ & $90-104$ & $105-119$ & $120-134$ & $>135$ \\
\hline grade & 1 & 2 & 3 & 4 & 5 & 6 & 7 & 8 & 9 & 10 \\
\hline
\end{tabular}

Thank you for participating. 


\section{References}

[1] Abbink, Klaus, and Sadrieh, Abdolkarim (1995) RatImage - Research assistance toolbox for computer-aided human behavior experiments, SFB Discussion Paper B-325, University of Bonn.

[2] Abbring, Jaap H., Van den Berg, Gerard J., and Van Ours, Jan C. (1997) The effect of unemployment insurance sanctions on the transition rate from unemployment to employment, mimeo, Tinbergen Institute, Amsterdam/Rotterdam.

[3] Black, Dan A., Smith, Jeffrey A., Berger, Mark C., and Noel, Brett J. (2003), Is the threat of training more effective than training itself? Evidence from random assignments in the UI system, American Economic Review, 93, 4, 1313-1327.

[4] Boone, Jan, and Van Ours, Jan C. (1999). Modelling financial incentives to get the unemployed back to work. CentER Working Paper, No. 00-02, Tilburg University.

[5] Boone, Jan, Fredriksson, Peter, Holmlund, Bertil, and Van Ours, Jan C. (2001) Optimal unemployment insurance with monitoring and sanctions, CentER Working Paper, No. 01-85, Tilburg University.

[6] Braunstein, Yale M., and Schotter, Andrew (1981) Economic search: an experimental study, Economic Inquiry, 19, 1-25.

[7] Braunstein, Yale M., and Schotter, Andrew (1981) Labor market search: an experimental study, Economic Inquiry, 20, 133-144.

[8] Camerer, Colin (1995) Choice under Risk and Uncertainty, in: John H. Kagel and Alvin E. Roth (eds.), Handbook of Experimental Economics, Princeton: Princeton University Press, 617-673.

[9] Cox, James C., and Oaxaca, Ronald L. (1989) Laboratory experiments with a finite horizon job search model, Journal of Risk and Uncertainty 2, 301-329.

[10] Cox, James C. and Oaxaca, Ronald L. (1992) Direct tests of the reservation wage property, Economic Journal 102, 1423-1432. 
[11] Fredriksson, Peter, and Holmlund, Bertil (2003) Improving incentives in unemployment insurance: a review of recent research, Working paper 2003:5, Uppsala: IFAU.

[12] Friedman, Daniel, and Sunder, Shyam (1994) Experimental Methods - A Primer for Economists, Cambridge: Cambridge University Press.

[13] Green, William (2000) Econometric analysis, New Jersey: Prentice Hall.

[14] Grubb, David (1999) Making work pay: the role of eligibility criteria for unemployment benefits, mimeo, Paris, OECD.

[15] Hey, John D. (1982) Search for rules for search, Journal of Economic Behavior and Organization 3, 65-81.

[16] Hey, John D. (1987) Still searching, Journal of Economic Behavior and Organization 8, 137-144.

[17] Jensen, Peter, Svarer Nielsen, Michael, and Rosholm, Michael (1999) The effects of benefits, incentives, and sanctions on youth unemployment, Working paper, 99-05, Aarhus.

[18] Kahneman, Daniel and Amos Tversky (1979) Prospect Theory: An Analysis of Decision Under Risk, Econometrica 47, 263-291.

[19] Lalive, Rafael, Van Ours, Jan C., and Zweimüller, Josef (2002) The effect of benefit sanctions on the duration of unemployment, CEPR-Discussion Paper 3311.

[20] Lippman, Steven A., and John J. McCall (1976a) The Economics of Job Search: A Survey: Part I, Economic Inquiry 14(2), 155-189.

[21] Lippman, Steven A., and John J. McCall (1976b) The Economics of Job Search: A Survey: Part II, Economic Inquiry 14(3), 347-368.

[22] Martin, John P., and Grubb, David (2001) What works and for whom: a review of OECD countries' experience with active labor market policies, Working Paper, OECD, Paris.

[23] Mortensen, Dale T. (1977) Unemployment insurance and job search decisions, Industrial and Labor Relations Review, 30, 505-517. 
[24] Selten, Reinhard, Abbink, Klaus, Buchta, Joachim, and Sadrieh, Abdolkarim (2003) How to play 3x3-games - a strategy method experiment, forthcoming in Games and Economic Behavior.

[25] Selten, Reinhard, Mitzkewitz, Michael, and Uhlich, Gerald R. (1997) Duopoly strategies programmed by experienced players, Econometrica, $65(3), 517-555$.

[26] Sonnemans, Joep (1998) Strategies of search, Journal of Economic Behavior and Organization 35, 309-332.

[27] Van den Berg, Gerard J., Van der Klaauw, Bas, and Van Ours, Jan C. (1998), Punitive sanctions and the transition rate from welfare to work, Discussion Paper, No. 9856, CentER for Economic Research, Tilburg University, forthcoming in Journal of Labor Economics (2004). 


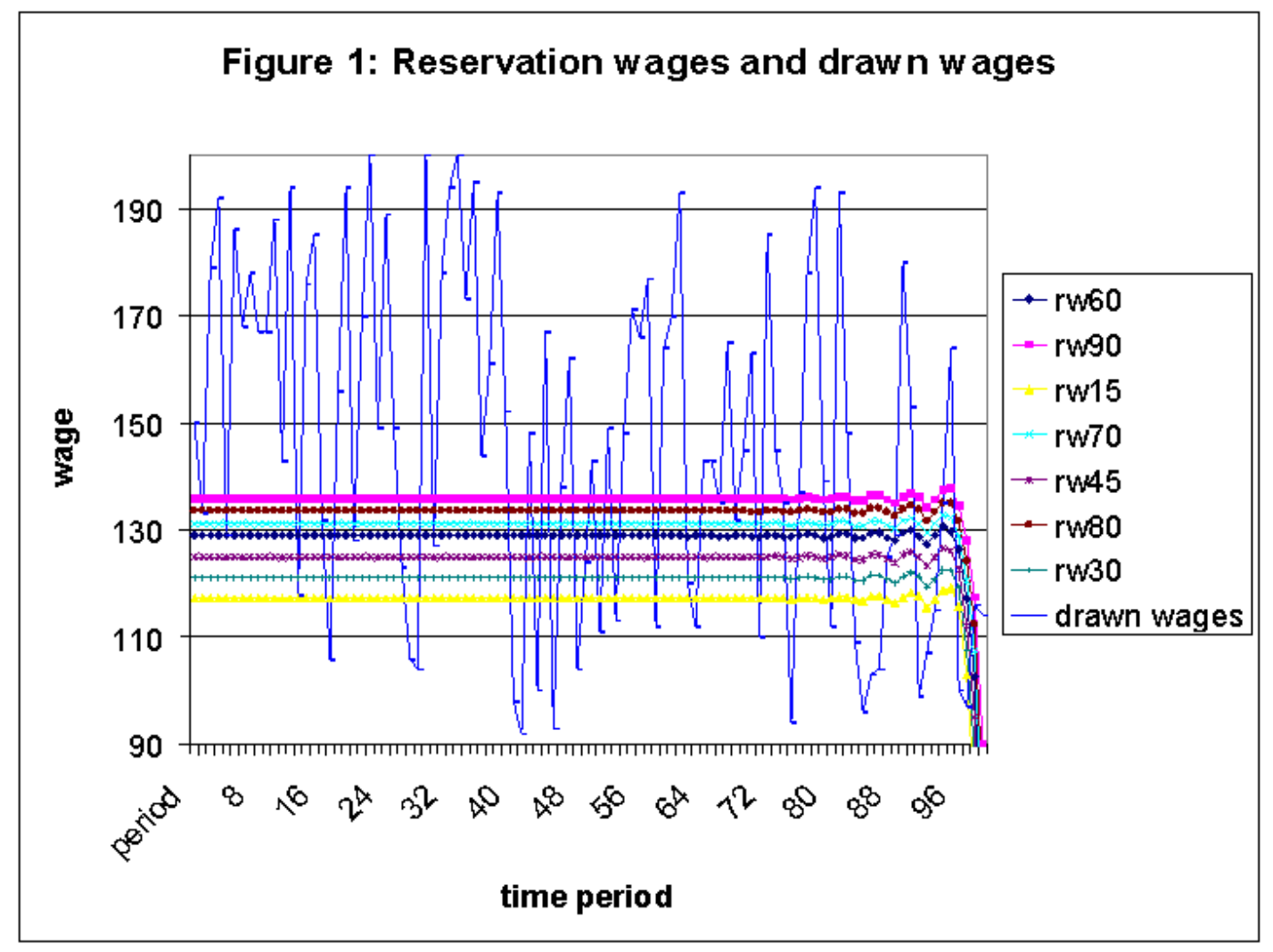

Figure 1: 